\title{
Baclofen and sleep apnoea syndrome: analysis of VigiBase, the WHO pharmacovigilance database
}

\author{
To the Editor:
}

Baclofen is a centrally acting gamma aminobutyric acid (GABA)-B agonist, widely used for chronic spasticity in neurological disorders, available in oral and intrathecal formulations. Depending on the severity of spasticity and tolerance, standard treatment includes daily oral administration of 40-80 mg [1]. The main adverse effects reported with baclofen are sedation, sleepiness, weakness, dizziness and psychological disturbances [2]. According to the depressant effects of GABA on the central nervous system, baclofen might also induce or aggravate sleep-disordered breathing by depressing central ventilatory drive and/or increasing upper airway obstruction. A single oral low dose of baclofen did not significantly impair the apnoea-hypopnoea index (AHI) in a population with moderate obstructive sleep apnoea [3], but bolus intrathecal administration of the drug increased central sleep apnoea (CSA) in patients with severe spasticity [4].

During the last decade, baclofen has been shown to be clinically effective for the treatment of alcohol addiction. A dose-dependent effect in reducing daily alcohol intake was suggested [5]. Even though randomised controlled trials have yielded conflicting results [6], in March 2014 the French health safety agency allowed the prescription of oral baclofen up to $300 \mathrm{mg} \cdot \mathrm{day}^{-1}$ for the treatment of alcohol dependence under a "temporary recommendation for use" license [7].

In this context, baclofen $200 \mathrm{mg} \cdot \mathrm{day}^{-1}$ has been shown as initiating severe CSA with an AHI of 81.6. $\mathrm{h}^{-1}$ [8]. Furthermore, Olivier et al. [9] described a case series of CSA attributed to oral baclofen therapy .

To investigate the safety signal for baclofen-related sleep apnoea syndrome (SAS) in a large pharmacovigilance database, we compared the reporting of SAS among baclofen users with users of other drugs by performing a disproportionality analysis within VigiBase over a 47-year time window and across different countries.

VigiBase, the WHO Global Individual Case Safety Reports (ICSRs) database, has been developed and maintained since 1978 by the Uppsala Monitoring Centre (UMC) the WHO Collaborating Center for Pharmacovigilance. In July 2017 it included more than 15 million ICSRs collected from 127 countries. Most reports came from Europe and North America, and were declared by health professionals, pharmaceutical companies or patients. They usually contain reporter information, patient characteristics (age, gender and medical history), a clinical description of the adverse drug reaction (ADR), its seriousness and evolution, drug exposures with dates, dosages and indications. Drugs are classified according to the Anatomical Therapeutic Chemical classification system. ADR coding is carried out using two different vocabularies: WHO-Adverse Reaction Terms (WHO-ART) and the Medical Dictionary for Regulatory Activities (MedDRA) [10].

We extracted from VigiBase all ICSRs with a MedDRA (version 20.0) Preferred Terms "sleep apnoea syndrome" code associated with baclofen, recorded from December 9, 1970, to July 30, 2017. A de-duplicated dataset was used.

The relationship between the use of baclofen and the occurrence of the ADR (i.e., SAS) was assessed by calculating the reporting odds ratio (ROR) associated with its $95 \%$ confidence interval (CI) in a casenoncase study compared to other drugs. ROR was calculated using the following formula [11]: $\mathrm{ROR}=(a / c) /$ $(b / d)$ with $a$ the number of SAS cases with baclofen, $b$ the number of ADRs other than SAS with baclofen,

@ERSpublications

Baclofen is associated with sleep apnoea syndrome especially the high oral doses prescribed for alcohol addiction http://ow.ly/J5H730h4znW

Cite this article as: Revol B, Jullian-Desayes I, Bailly S, et al. Baclofen and sleep apnoea syndrome: analysis of VigiBase, the WHO pharmacovigilance database. Eur Respir J 2018; 51: 1701855 [https://doi. org/10.1183/13993003.01855-2017]. 
$c$ the number of SAS with all other drugs in VigiBase and $d$ the number of ADRs with all other drugs in VigiBase excepting SAS. A ROR value $>2$ with the number of cases $\geqslant 5$ was considered to be significant [12]. Our secondary analyses studied the variation in reporting rate across years and countries with the same approach.

Of the 15083681 ICSRs reported to VigiBase between December 1970 and July 2017, 7459 (0.05\%) were SAS cases. Among the ADRs with exposure to baclofen, there were 50 cases of SAS and 23507 other adverse reactions. The majority of SAS cases attributed to exposure to baclofen originated from America and Europe (29 and 20 respectively) and were reported after 2013 (86\%). In total, 44\% of the patients with baclofen-related cases of SAS were also exposed to other drugs recognised to induce or aggravate sleep disordered breathing, such as opioids or benzodiazepines [13].

Among the countries which reported that at least five cases, the sex ratio and age were not statistically different between the USA $(n=29)$ and France $(n=16)$. On the contrary, indications, administration route and dosages were very different. Alcohol dependence $(n=12)$ and binge eating disorders $(n=3)$ were only reported in France, with a mean daily oral dose of $125 \mathrm{mg}$, whereas the intrathecal route was mainly reported in the USA $(n=23)$, with a mean daily dose of $1.1 \mathrm{mg}$ for chronic spasticity.

In July 2017 the use of baclofen was associated with a global increased reporting of SAS compared with other drugs (ROR 4.32, $\mathrm{n}=50,95 \%$ CI 3.27-5.71). ROR ranged from $1.90(\mathrm{n}=29,95 \%$ CI $1.32-2.74)$ in the USA to 110.97 ( $n=16,95 \%$ CI $62.40-197.33)$ in France. The year-by-year analysis of cumulative ROR of SAS associated with baclofen is presented in figure 1. The pharmacovigilance signal became significant in 2014. If a ROR value $>2$ is considered as significant, then the pharmacovigilance signal is questionable in the USA. The signal is 50 times higher in France, since 2014 when the first French case was reported.

We used a case-noncase design to evaluate the association between the use of baclofen and the reporting of SAS in the WHO drug adverse event database. Reports of SAS as an ADR appear to be rare and probably underestimated [14]. Despite the well-known problem of underreporting in pharmacovigilance, a significant disproportionality signal was found. The year-by-year analysis combined with the geographic analysis confirmed a major French safety signal, associated with oral high doses of baclofen mainly for the treatment of alcohol dependence since 2014, suggesting a dose-dependent effect. The difference in ROR between France and the USA is probably explained by different indications, administration route and dosages of baclofen. Thus we cannot exclude that baclofen impaired a previous unknown condition, as alcohol increases the risk of sleep apnoea itself [15].

Our result has to be considered as a pharmacovigilance signal, confirming previous observations with baclofen for alcoholism [8,9]. Interestingly, this signal emerged in 2014, 1 year before the first case report, avoiding a notoriety bias. However, it is important to note that the information about age, gender, baclofen indication or dose, polysomnographic testing and outcome are not systematically available in pharmacovigilance databases. An important limitation is the large number of cases in which baclofen was

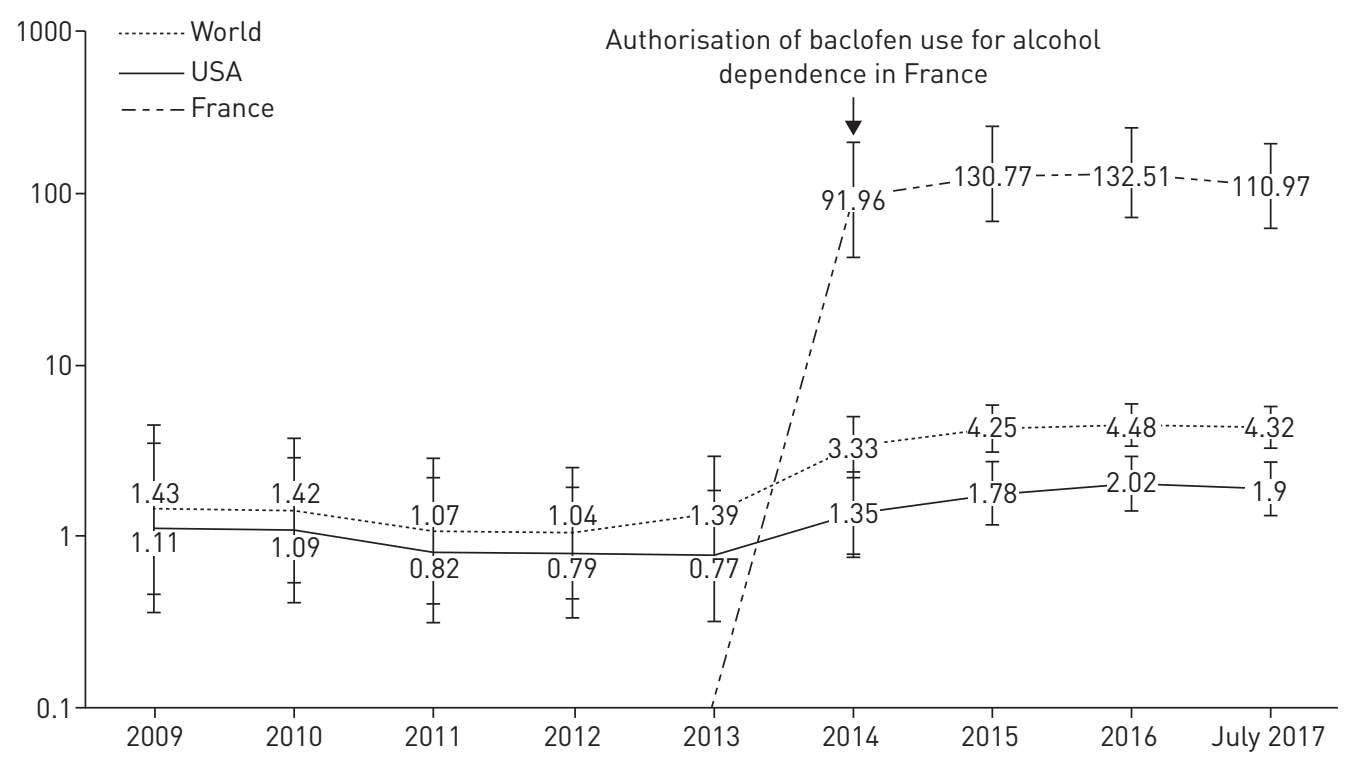

FIGURE 1 Year-by-year analysis of cumulative reporting odds ratio for sleep apnoea syndrome associated with baclofen use. 
associated with other drugs known to induce sleep-disordered breathing [13]. The lack of a gold standard is another problem in any assessment using signal detection methods. No one method was found to be uniformly better than the others and the limits of the current disproportionality statistics are similar [12].

Despite its authorised usage in the management of alcohol dependence in France, there is growing caution concerning baclofen use. At high doses, it could be associated with an increased risk of hospitalisation and death compared with other treatments for alcohol dependence, according to the results of a recent study conducted by the French health safety agency [16]. Finally, the 2014 "temporary recommendation for use" was modified in July 2017, to a maximum oral daily dose of $80 \mathrm{mg}$. There is currently a heated debate between the health authorities, patient groups and physicians regarding this indication. We think our results are of interest in this context.

Bruno Revol $\circledast^{1,2,3}$, Ingrid Jullian-Desayes ${ }^{1,2}$, Sébastien Bailly ${ }^{1,2}$, Michel Mallaret ${ }^{3}$, Renaud Tamisier $\circledast^{1,2}$, Marie-Sara Agier ${ }^{4}$, Frédéric Lador $\oplus^{5}$, Marie Joyeux-Faure ${ }^{1,2,6}$ and Jean-Louis Pépin ${ }^{1,2,6}$

${ }^{1} \mathrm{HP} 2$ laboratory, Inserm U1042 unit, University Grenoble Alps, Grenoble, France. ${ }^{2}$ EFCR laboratory, Thorax and Vessels, Grenoble Alps University Hospital, Grenoble, France. ${ }^{3}$ Pharmacovigilance Dept, Grenoble Alps University Hospital, Grenoble, France. ${ }^{4}$ Pharmacovigilance Dept, Tours University Hospital, Tours, France. ${ }^{5}$ Sleep Laboratory and Division of Pulmonology, Dept of Medicine Specialties, Geneva University Hospitals, Geneva, Switzerland. ${ }^{6}$ These authors contributed equally to this work.

Correspondence: Jean-Louis Pépin, Laboratoire EFCR, CHU Grenoble Alpes, CS 10217, 38043 Grenoble cedex 09, France. E-mail: JPepin@chu-grenoble.fr

Received: Sept 142017 | Accepted after revision: Oct 202017

Support statement: This work was supported by the French National Research Agency in the framework of the "Investissements d'avenir" programme (ANR-15-IDEX-02). Funding information for this article has been deposited with the Crossref Funder Registry.

Conflict of interest: None declared.

Acknowledgements: The authors would like to thank the UMC that provided and gave permission to use the data analysed in the present study. Results and conclusions are those of the authors and not necessarily those of the National Centers, UMC or WHO. We thank Alison Foote (Grenoble Alps University Hospital, France) for critically editing the manuscript.

\section{References}

1 Bauman WA, La Fountaine MF, Cirnigliaro CM, et al. Low-dose baclofen therapy raised plasma insulin-like growth factor-1 concentrations, but not into the normal range in a predictable and sustained manner in men with chronic spinal cord injury. J Spinal Cord Med 2013; 36: 476-482.

2 Dario A, Tomei G. A benefit-risk assessment of baclofen in severe spinal spasticity. Drug Saf 2004; 27: 799-818.

3 Finnimore AJ, Roebuck M, Sajkov D, et al. The effects of the GABA agonist, baclofen, on sleep and breathing. Eur Respir J 1995; 8: 230-234.

4 Bensmail D, Marquer A, Roche N, et al. Pilot study assessing the impact of intrathecal baclofen administration mode on sleep-related respiratory parameters. Arch Phys Med Rehabil 2012; 93: 96-99.

5 Addolorato G, Leggio L, Ferrulli A, et al. Dose-response effect of baclofen in reducing daily alcohol intake in alcohol dependence: secondary analysis of a randomized, double-blind, placebo-controlled trial. Alcohol Alcohol 2011; 46: 312-317.

6 Brennan JL, Leung JG, Gagliardi JP, et al. Clinical effectiveness of baclofen for the treatment of alcohol dependence: a review. Clin Pharmacol Adv Appl 2013; 5: 99-107.

7 Emmerich J, Dumarcet N, Lorence A. France's new framework for regulating off-label drug use. N Engl J Med 2012; 367: 1279-1281

8 Perogamvros L, Pépin JL, Thorens G, et al. Baclofen-associated onset of central sleep apnea in alcohol use disorder: a case report. Respir Int Rev Thorac Dis 2015; 90: 507-511.

9 Olivier P-Y, Joyeux-Faure M, Gentina T, et al. Severe central sleep apnea associated with chronic baclofen therapy: a case series. Chest 2016; 149: e127-e131.

10 Lindquist M. VigiBase, the WHO Global ICSR Database system: basic facts. Drug Inf J 2008; 42: 409-419.

11 Wilson AM, Thabane L, Holbrook A. Application of data mining techniques in pharmacovigilance. $\mathrm{Br} J \mathrm{Clin}$ Pharmacol 2004; 57: 127-134.

12 Candore G, Juhlin K, Manlik K, et al. Comparison of statistical signal detection methods within and across spontaneous reporting databases. Drug Saf 2015; 38: 577-587.

13 Jullian-Desayes I, Revol B, Chareyre E, et al. Impact of concomitant medications on obstructive sleep apnoea. $\mathrm{Br} \mathrm{J}$ Clin Pharmacol 2017; 83: 688-708.

14 Linselle M, Sommet A, Bondon-Guitton E, et al. Can drugs induce or aggravate sleep apneas? A case-noncase study in VigiBase $\left({ }^{*}\right)$, the WHO pharmacovigilance database. Fundam Clin Pharmacol 2017; 31: 359-366.

15 Choi SJ, Lee SI, Joo EY. Habitual alcohol consumption and metabolic syndrome in patients with sleep disordered breathing. PloS One 2016; 11: e0161276.

16 Résultats de l'étude sur les usages et la sécurité du baclofène en France entre 2009 et 2015 - Communiqué ANSM : Agence nationale de sécurité du médicament et des produits de santé. n.d. http://ansm.sante.fr/Sinformer/Actualite/Resultats-de-l-etude-sur-les-usages-et-la-securite-du-baclofene-en-France-entre-2009-et-2015Communique. Date last accessed: July 21, 2017. 